\title{
Dialysis Disequilibrium Syndrome: A Swell Diagnosis?
}

\author{
Diane Donegan $^{\mathrm{a}, \mathrm{d}}$, Kianoush Kashani ${ }^{\mathrm{b}, \mathrm{c}}$
}

\begin{abstract}
Dialysis disequilibrium syndrome (DDS) is a known complication of dialysis with a wide spectrum of clinical presentations including self-limiting nausea, to the extreme version of it resulting in coma and death. The differing clinical presentations are the result of the varying severity of increased intracranial pressure. Preventative measures have made its occurrence much less frequent, but its diagnosis should be considered when neurological symptoms are temporally related to dialysis even when preventative measures have been implemented. We report the case of a patient with acute kidney injury (AKI) in the setting of chronic kidney disease (CKD) who developed DDS following initial dialysis despite precautionary measures.
\end{abstract}

Keywords: Disequilibrium; Dialysis; Renal failure

\section{Introduction}

Dialysis disequilibrium syndrome (DDS) is an uncommon complication in those with advanced chronic kidney disease (CKD) who have been initiated on hemodialysis and rarely peritoneal dialysis. Treatment is primarily preventative, but occasionally therapeutic measures aimed at reducing intracranial pressure, are necessary despite precautionary measures. We report a case of DDS in a patient with severe acute kidney injury (AKI) despite preventative measures. We will

Manuscript accepted for publication July 7, 2014

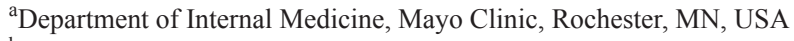

${ }^{\mathrm{b}}$ Division of Nephrology and Hypertension, Mayo Clinic, Rochester,

MN, USA

${ }^{\mathrm{c}}$ Division of Pulmonary and Critical Care, Mayo Clinic, Rochester, MN, USA

${ }^{\mathrm{d}}$ Corresponding Author: Diane Donegan, Mayo Clinic, 200 First Street SW, Rochester, MN 55905, USA. Email: donegan.diane@mayo.edu

doi: http://dx.doi.org/10.14740/jmc1847w review the postulated pathophysiology underlying the syndrome.

\section{Case Report}

A 76-year-old female was transferred from an outside facility to a tertiary healthcare center with altered mental status and hypoglycemia. She admitted to 4 weeks of diarrhea, decreased oral intake, 10 pounds weight loss (body surface area was $1.42 \mathrm{~m}^{2}$ ), fatigue and lassitude. Her past medical history was significant for coronary artery disease, hypertension controlled with hydrochlorothiazide and lisinopril, hyperlipidemia, and diabetes mellitus type II for which she was taking glargine and glimepiride. Her diabetes was complicated by retinopathy and stage III CKD with a baseline serum creatinine of $1.2 \mathrm{mg} / \mathrm{dL}$. Her initial laboratory investigations revealed a blood urea nitrogen $(\mathrm{BUN})>110 \mathrm{mg} /$ $\mathrm{dL}$, creatinine $8.2 \mathrm{mg} / \mathrm{dL}$, sodium $142 \mathrm{mmol} / \mathrm{L}$, potassium $3.6 \mathrm{mmol} / \mathrm{L}, \mathrm{pH} 7.18$ and bicarbonate of $8 \mathrm{mmol} / \mathrm{L}$ with a high anion gap of 22. Non-contrast CT brain imaging did not reveal any hemorrhage, mass or mass effect.

On arrival she was poorly responsive. Her glucose was found to be $19 \mathrm{mg} / \mathrm{dL}$ and was treated with a bolus of $50 \%$ dextrose. She was started on a $0.9 \%$ saline $/ 5 \%$ dextrose drip with $40 \mathrm{mEq}$ of potassium at $150 \mathrm{~mL} / \mathrm{h}$. Dextrose was escalated to $10 \%$ to maintain glucose levels. In addition, $0.45 \%$ saline with $75 \mathrm{mEq}$ of sodium bicarbonate was given at a rate of $200 \mathrm{~mL} / \mathrm{h}$ given her acidemia. Urinalysis revealed a red blood cell count of $<3$ per high power field (HPF), white cell count 4 - 10/HPF and renal epithelial cells 1 - 2 per HPF with no other significant proteinuria or sediments. Renal ultrasound showed bilateral thin cortices; no hydronephrosis was noted. Clinical impression, based on the clinical history and biochemical data, pointed to stage III AKI based on the KDIGO criteria [1] on a background of CKD stage III with baseline estimated glomerular filtration rate (eGFR) of 44 $\mathrm{mL} / \mathrm{min}$ per body surface area. This was felt to be due to decreased intravascular volume as a result of diarrhea, poor oral intake and nausea, exacerbated by diuretic and ACE inhibitor use.

Correction of hypoglycemia led to a significant im- 


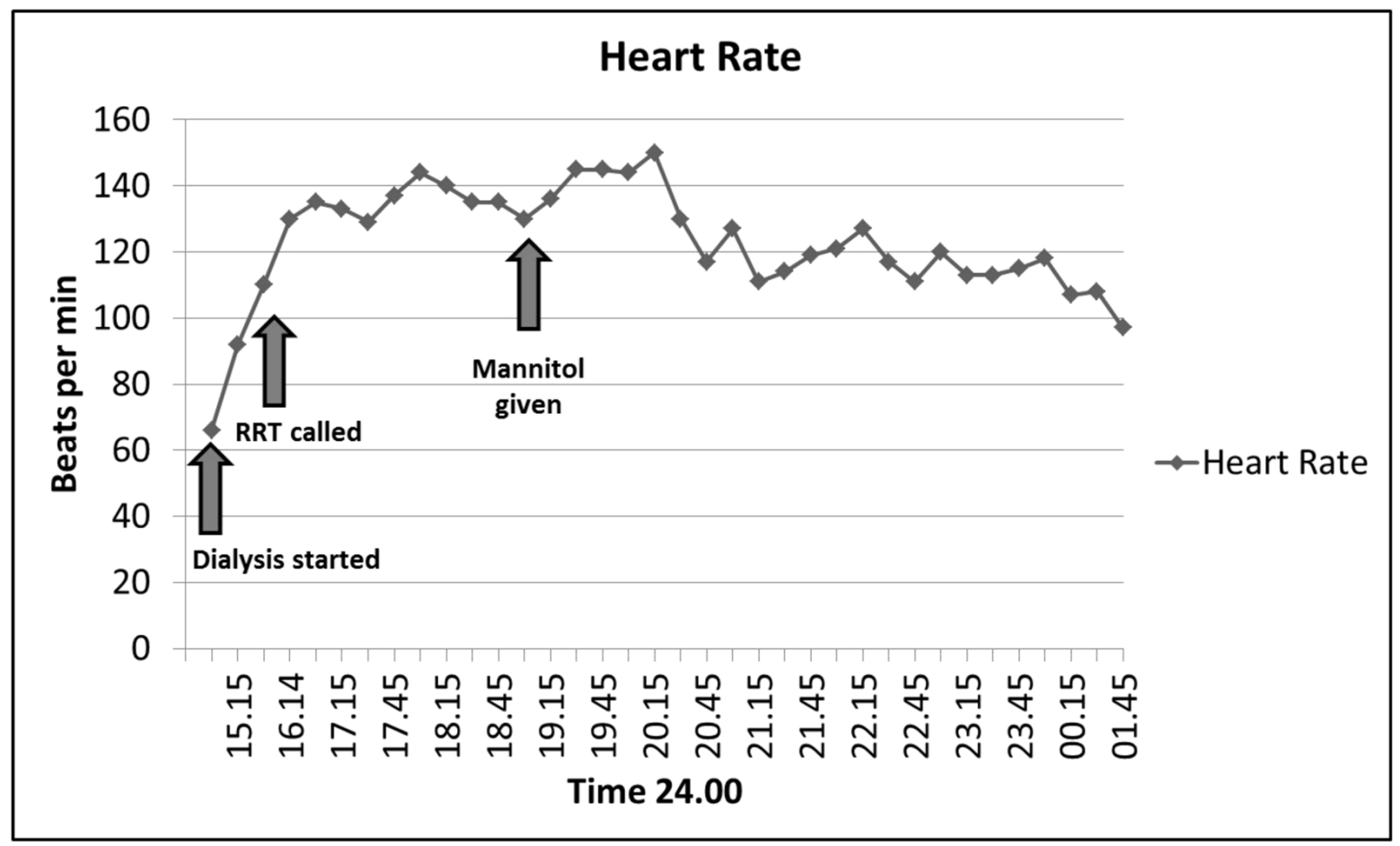

Figure 1. Heart response to mannitol administration. Tachycardia (atrial fibrillation with rapid ventricular response) noted during dialysis resulted in an RRT call. Heart rate remained elevated until mannitol was administered as shown below.

provement in her mentation and was felt to be at baseline according to her family; however, due to persistent fatigue, nausea, oliguria and persistent acidemia the decision was made to initiate renal replacement therapy with the infusion of $2 \mathrm{~L}$ of $0.9 \%$ saline. She proceeded to dialysis using a dialysate flow rate of $600 \mathrm{~mL} / \mathrm{min}$, a blood flow rate of 250 $\mathrm{mL} / \mathrm{min}$ and bicarbonate of $37 \mathrm{mmol} / \mathrm{L}$ for a total duration of $2 \mathrm{~h}$ using a Gambro polyflux $140 \mathrm{H}$ dialyzer. After 45 min of dialysis the patient was noted to be agitated, delirious and "thrashing", but responsive. She was tachycardic at the rate of $140 \mathrm{bpm}$ with systolic blood pressure ranging from 94 to $100 \mathrm{~mm} \mathrm{Hg}$ and a glucose level of $238 \mathrm{mg} / \mathrm{dL}$. At this time sodium measured was $139 \mathrm{mmol} / \mathrm{L}$, potassium was 2.5 $\mathrm{mmol} / \mathrm{L}$, creatinine was $2.9 \mathrm{mg} / \mathrm{dL}$ and BUN was $64 \mathrm{mg} / \mathrm{dL}$ representing a urea reduction ratio on $52 \%$. Potassium was corrected with $60 \mathrm{mEq}$ of potassium chloride. The rapid response team (RRT) was notified. Dialysis was stopped and 1 L $0.9 \%$ saline bolus was administered which did not improve her tachycardia or agitation. Electrocardiogram revealed atrial fibrillation with a rapid ventricular response. She was transferred to the medical intensive care unit (MICU).

On admission to the MICU, she was noted to be delirious and restless. Repeat laboratory testing revealed sodium of $146 \mathrm{mmol} / \mathrm{L}$, potassium of $4 \mathrm{mmol} / \mathrm{L}$, BUN of $60 \mathrm{mg} /$ $\mathrm{dL}$, along with creatinine of $3.1 \mathrm{mg} / \mathrm{dL}$ and bicarbonate of $12 \mathrm{mmol} / \mathrm{L}$. Given that her symptoms had occurred during dialysis, despite a shorter run time and a lower blood flow rate, DDS was considered. She was given $2.5 \mathrm{mg}$ of haloperidol for delirium with no major change in her clinical presentation. Subsequently she was given $10 \mathrm{~g}$ of mannitol to increase intravascular osmolarity. After the mannitol infusion her heart rate decreased with restoration of sinus rhythm to a rate of 90 - 110 beats per minute (Fig. 1) and her agitation resolved. She received ongoing resuscitation with $2 \mathrm{~L}$ of Ringers lactate and 2 units of packed red blood cells as her hemoglobin had dropped to $7.4 \mathrm{mg} / \mathrm{dL}$ (attributed to hemodilution) and cardiac rhythm reverted to sinus.

Following the initial dialysis she required no further dialysis as urine output increased with a return of her creatinine to baseline $(1.1 \mathrm{mg} / \mathrm{dL})$. At follow-up, creatinine remained stable at $1.1 \mathrm{mg} / \mathrm{dL}$ (eGFR of $50 \mathrm{~mL} / \mathrm{min}$ per body surface area).

\section{Discussion}

DDS is a known complication in those with advanced renal dysfunction initiated on dialysis and was first described in 1962 [2]. We report the case of a patient who developed AKI with associated uremic symptoms and persistent metabolic acidosis necessitating dialysis which was complicated by DDS despite implementation of recommended precautionary measures.

The diagnosis of DDS is one of exclusion and can present 
with nausea, vomiting, headache, blurred vision, hypertension, disorientation and restlessness attributable to cerebral edema and increasing intracranial pressure following dialysis. When severe it may result in seizures, coma and death $[3,4]$. Alternative causes of these non-specific symptoms, including stroke or hypoglycemia, should be considered. Its onset is usually towards the end of dialysis and occurs more commonly in children, the elderly, those with a smaller body mass index (an indicator of reduced volume of distribution), severe azotemia and in those with pre-existing neurological disease [5]. Our patient had several identifiable risk factors placing her at high risk of DDS including age, severe uremia with a BUN of 142, low body surface area $1.42 \mathrm{~m}^{2}$ and profound acidosis (bicarbonate $8 \mathrm{mmol} / \mathrm{L}$ ).

The etiology of DDS remains debated with several postulated theories. The first, termed the "reverse urea effect", is based on the fact that urea is removed more slowly from the central nervous system (CNS) than blood during rapid dialysis creating a concentration gradient [6]. This promotes the movement of water into the brain resulting in increased intracranial pressure. Diffusion-weighted magnetic resonance imaging of the brain in those with severe azotemia before and after dialysis revealed measurable changes most consistent with interstitial edema [7].

Urea is felt to be an ineffective osmole due to its small molecular size and ability to cross cell membranes. However, the reflection coefficient of urea at the blood brain barrier (BBB), which represents the effectiveness of a solute (urea) in generating an osmotic force at the blood brain barrier, is measured to be 0.44 in rabbits (with 0 generating no osmotic force and 1 generating maximal osmotic force) [8]. This may explain how a delay in diffusion of urea across the BBB creates an osmolar gradient, promoting the movement of water resulting in cerebral edema. The delay in diffusion of urea has been attributed to an adaptive decrease in urea transporters. Studies in uremic rats revealed a compensatory decrease in the concentration of urea transporter B1 (UT-B1) and an increase in aquaporin channels (AQP-4, AQP-9). In the setting of rapid dialysis, this allows for rapid water transportation into the brain in the setting of a slower recovery of the osmolar gradient [9].

Against this theory is the fact that the osmolar gradient cannot be solely attributed to the urea or any other measured osmole, and raises the possibility of the development of "idiogenic osmoles". These osmoles are organic molecules that are made by adaptive brain cells in the setting of chronic uremia. It is thought that the ability of these molecules to move across BBB is poor, and therefore they participate in the osmolar gradient needed for water movement into CNS [10].

In addition, despite severe acidosis, $\mathrm{CSF} \mathrm{pH}$ is measured to be normal. However, during rapid dialysis $\mathrm{CSF} \mathrm{pH}$ and intracellular $\mathrm{pH}$ unexpectedly decrease as arterial $\mathrm{pH}$ increases [11]. This may contribute to increased osmolarity by: 1) an increase in intracellular protons displacing protein bound anions which, when unbound, are osmotically active; or 2) the retention or formation of "protective osmoles" or organic acids.

Irrespective of either theory the net effect is cerebral edema and raised intracranial pressure which can be prevented or treated $[12,13]$. Prevention is aimed at minimizing a reduction in osmolar gradient through a shorter dialysis run, slower blood and dialysate flow rates, a dialyzer with smaller mass transfer area coefficient (KoA), using concurrent blood-dialysate flows, increasing the dialysate sodium concentration or administering an osmotically active agent during dialysis e.g., urea or mannitol. Should symptoms suggestive of DDS develop during dialysis, slowing or stopping dialysis may be effective and symptomatic management may be adequate in most of cases with minor signs of intracranial hypertension such as nausea. In the event of severe symptoms, raising the plasma osmolality through the use of hypertonic saline, glucose, glycerol or mannitol, as in our patient, may be required. When high glucose dialysate was compared to mannitol, mannitol was found to be superior [14]. There is, however, no current consensus on the dose of mannitol required.

\section{Conclusion}

DDS is a known possible complication of dialysis which typically occurs in those with severe azotemia in the setting of advance CKD. While the pathophysiology is debated, it ultimately leads to cerebral edema and increased intracranial pressure. If severe, the outcome can be fatal. We report the case of a patient with AKI with severe azotemia and acidosis necessitating dialysis who developed DDS despite only $1 \mathrm{~h}$ of dialysis and who was successfully treated with mannitol.

\section{Conflict of Interest}

The authors declare there is no conflict of interests.

\section{References}

1. Khwaja A. KDIGO Clinical Practice Guidelines for Acute Kidney Injury. Nephron Clin Pract. 2012;120(4):179184.

2. Kennedy AC, Linton AL, Eaton JC. Urea levels in cerebrospinal fluid after haemodialysis. Lancet. 1962;1(7226):410-411.

3. Grushkin CM, Korsch B, Fine RN. Hemodialysis in small children. JAMA. 1972;221(8):869-873.

4. Bagshaw SM, Peets AD, Hameed M, Boiteau PJ, Laupland KB, Doig CJ. Dialysis Disequilibrium Syndrome: brain death following hemodialysis for metabolic acido- 
sis and acute renal failure--a case report. BMC Nephrol. 2004;5:9.

5. Peterson H, Swanson AG. Acute Encephalopathy Occuring during Hemodialysis. The Reverse Urea Effect. Arch Intern Med. 1964;113:877-880.

6. Silver SM, DeSimone JA, Jr., Smith DA, Sterns RH. Dialysis disequilibrium syndrome (DDS) in the rat: role of the "reverse urea effect". Kidney Int. 1992;42(1):161166.

7. Chen CL, Lai PH, Chou KJ, Lee PT, Chung HM, Fang HC. A preliminary report of brain edema in patients with uremia at first hemodialysis: evaluation by diffusion-weighted MR imaging. AJNR Am J Neuroradiol. 2007;28(1):68-71.

8. Kleeman CR, Davson H, Levin E. Urea transport in the central nervous system. Am J Physiol. 1962;203:739747.

9. Trinh-Trang-Tan MM, Cartron JP, Bankir L. Molecular basis for the dialysis disequilibrium syndrome: altered aquaporin and urea transporter expression in the brain.
Nephrol Dial Transplant. 2005;20(9):1984-1988.

10. Arieff AI, Massry SG, Barrientos A, Kleeman CR. Brain water and electrolyte metabolism in uremia: effects of slow and rapid hemodialysis. Kidney Int. 1973;4(3):177187.

11. Arieff AI. Dialysis disequilibrium syndrome: current concepts on pathogenesis and prevention. Kidney Int. 1994;45(3):629-635.

12. Esnault P, Lacroix G, Cungi PJ, D’Aranda E, Cotte J, Goutorbe P. Dialysis disequilibrium syndrome in neurointensive care unit: the benefit of intracranial pressure monitoring. Crit Care. 2012;16(6):472.

13. Bertrand YM, Hermant A, Mahieu P, Roels J. Intracranial pressure changes in patients with head trauma during haemodialysis. Intensive Care Med. 1983;9(6):321-323.

14. Rodrigo F, Shideman J, McHugh R, Buselmeier T, Kjellstrand C. Osmolality changes during hemodialysis. Natural history, clinical correlations, and influence of dialysate glucose and intravenous mannitol. Ann Intern Med. 1977;86(5):554-561. 